\title{
Asenapine monotherapy in the acute treatment of both schizophrenia and bipolar I disorder
}

This article was published in the following Dove Press journal:

Neuropsychiatric Disease and Treatment

2I September 2009

Number of times this article has been viewed

\author{
Delia Bishara' \\ David Taylor ${ }^{1,2}$ \\ 'Pharmacy Department, South London \\ and Maudsley NHS Foundation Trust, \\ Denmark Hill, London, UK; ${ }^{2}$ Division \\ of Pharmaceutical Sciences, King's \\ College, London, UK
}

\begin{abstract}
Asenapine is a new atypical antipsychotic agent currently under development for the treatment of schizophrenia and bipolar disorder. It has high affinity for various receptors including antagonism at $5 \mathrm{HT}_{2 \mathrm{~A}}, 5 \mathrm{HT}_{2 \mathrm{~B}}, 5 \mathrm{HT}_{2 \mathrm{C}}, 5 \mathrm{HT}_{6}$ and $5 \mathrm{HT}_{7}$ serotonergic receptor subtypes, $\alpha_{1 \mathrm{~A}}, \alpha_{2 \mathrm{~A}}, \alpha_{2 \mathrm{~B}}$ and $\alpha_{2 \mathrm{C}}$ adrenergic and $\mathrm{D}_{3}$ and $\mathrm{D}_{4}$ dopaminergic receptors. As with other atypicals, asenapine exhibits a high $5 \mathrm{HT}_{2 \mathrm{~A}}: \mathrm{D}_{2}$ affinity ratio. Although similar to clozapine in its multitarget profile, it shows no appreciable affinity for muscarinic receptors. Asenapine has shown efficacy in alleviating both positive and negative symptoms of schizophrenia compared with placebo. Although promising, further studies are required in order to determine whether it has advantages over placebo and other antipsychotics in alleviating cognitive impairment associated with schizophrenia. It has also shown long-term efficacy comparable with olanzapine in bipolar I disorder. Asenapine is generally well tolerated and appears to be metabolically neutral. It has low propensity to cause weight gain and prolactin elevation. There were no concerns in the studies about its effects on the cardiovascular system and QTc prolongation. The incidence of extrapyramidal symptoms with asenapine however has been found to be higher than that with olanzapine. It may be a useful alternative to aripiprazole in schizophrenia and bipolar disorder in patients who are at high risk of metabolic abnormalities.
\end{abstract}

Keywords: asenapine, schizophrenia, bipolar I disorder, antipsychotics

\section{Introduction \\ Schizophrenia}

The symptoms of schizophrenia are thought to result from the dysfunction of several neurotransmitters mainly dopamine ${ }^{1}$ and serotonin ${ }^{2}$ although noradrenaline, acetylcholine and glutamate have also been implicated. ${ }^{3}$ The multidimensional facet of the disorder means that life-long therapeutic intervention with psychotropic agents and principally antipsychotics is often warranted. Although the specific mechanism of action of antipsychotics is still not fully understood, the antagonism of dopamine transmission is likely to play a major role. The dopamine system affects the mesolimbic, striatal and cortical areas of the brain. Neurones in the midbrain release dopamine which interacts with dopamine receptors. Antipsychotics block dopaminergic transmission by binding to these dopamine receptors, in particular $\mathrm{D}_{2}$ receptors, the affinity for which correlates with the clinical dose in many cases. ${ }^{4}$

The history of antipsychotic drug development has been haphazard. In 1952, the accidental use of chlorpromazine revolutionized the treatment of schizophrenia. In the following years, several other first-generation or typical antipsychotics were launched and although this group of antipsychotic agents were effective in managing the positive 
symptoms of schizophrenia, they demonstrated relatively poor efficacy for negative symptoms and associated cognitive impairment. Typical antipsychotics have also been associated with severe and devastating extrapyramidal symptoms (EPS) ${ }^{5}$ and tardive dyskinesia, ${ }^{6}$ thus limiting their long-term use. In addition, adverse effects relating to elevation in serum prolactin ${ }^{7}$ also made their use problematic. It is thought that the blockade of dopamine $\mathrm{D}_{2}$ receptors is responsible for the antipsychoticinduced movement disorders and rise in prolactin. ${ }^{4}$

The introduction of second generation, or atypical antipsychotics, over the last 20 years has contributed considerably to the advancement in the treatment of schizophrenia, both in terms of scope of efficacy and more favorable tolerability in some respects. Atypical antipsychotics have demonstrated clinical effectiveness comparable to that with typical antipsychotics with regards to positive symptoms ${ }^{8}$ and are argued to be more effective in the management of negative symptoms ${ }^{9,10}$ and cognitive impairment. ${ }^{11,12}$ Moreover, they are associated with a significantly lower incidence of EPS. ${ }^{13}$ As a result, atypicals quickly replaced the older typical antipsychotics and for many years they were considered the treatment of choice in the management of schizophrenia. ${ }^{14}$

The atypical antipsychotic clozapine which was actually synthesized shortly after chlorpromazine in the 1950s, has a unique pharmacological profile in view of its affinity for a diverse range of receptors. These include $\mathrm{D}_{1}, \mathrm{D}_{2}$ and $\mathrm{D}_{4}$ dopaminergic, $\alpha_{1}$ and $\alpha_{2}$ adrenergic, $H_{1}$ histaminergic and muscarinic receptors as well as various serotonin receptor subtypes. ${ }^{15}$ Consequently, clozapine has unique properties in the prevention of suicide ${ }^{16}$ and treatment-refractory schizophrenia (TRS), ${ }^{17}$ although there has been some suggestion that other antipsychotics such as olanzapine may also be effective in TRS at higher than typically prescribed doses. ${ }^{18}$ In addition to clozapine's superior efficacy profile, it has a more favorable motor system side effect profile, with minimal risk of causing EPS or tardive dyskinesia. ${ }^{19}$ Its use however is somewhat limited by its potential to cause neutropenia and agranulocytosis, ${ }^{20}$ of possibly fatal consequence if it were not for the strict haematological monitoring requirements which are obligatory with the use of clozapine.

Several hypotheses have been put forward to explain the differences in clinical and adverse effect profiles between typical and atypical antipsychotic drugs. It has been suggested that atypical drugs have a stronger $5 \mathrm{HT}_{2 \mathrm{~A}}$ receptor affinity compared with that for the $\mathrm{D}_{2}$ receptor $^{21}$ leading to their lower propensity to cause EPS and prolactin elevation. This hypothesis, however, has been challenged with the suggestion that the "atypicality" of atypical agents is actually due to the fast dissociation from the $\mathrm{D}_{2}$ receptor, resulting in transient and easily reversible occupancy of this receptor. ${ }^{22}$ In addition, the fact that atypicals have a moderate $D_{2}$ receptor occupancy ${ }^{23}$ compared with typicals has also been proposed as an explanation for their different profiles.

However, despite atypicals having shown more favorable tolerability for movement disorders and prolactin-related adverse effects, other serious safety concerns have surfaced over the years with certain agents in this class. Metabolic ${ }^{24}$ and cardiovascular disease ${ }^{25}$ including weight gain, increased plasma lipids, new onset diabetes, prolongation of QTc interval and sudden death are the most concerning adverse effects of atypical agents, which were once considered relatively safe.

In the last decade, drug development in the field of schizophrenia has slowed somewhat, with the only advancement having been the introduction of the dopamine partial agonist, aripiprazole. Dopamine partial agonists are thought to exert their effects by acting as dopamine antagonists in the mesolimbic system where there is a high concentration of dopamine, however, in the mesocortical system where reduced dopamine activity is thought to produce negative symptoms and cognitive impairment, they act as dopamine agonists, thus the concept of dopamine system stabilization. ${ }^{26,27}$ Since the launch of aripiprazole in 2004, no new antipsychotics have emerged on the market.

\section{Bipolar disorder}

The complexities of managing bipolar disorder are numerous. Firstly, the diagnostic criteria used for diagnosing bipolar disorder by psychiatrists in different parts of the world varies, resulting in a lack of clear distinction between schizophrenia and bipolar disorder thus influencing the management of the condition worldwide. Secondly, different treatments need to be considered separately for the specific manic, hypomanic, mixed and depressive episodes in addition to whether control of the acute state or maintenance of therapy is required. Furthermore, the pathogenesis and neurochemistry of bipolar disorder remains unclear, although serotonergic, noradrenergic and dopaminergic transmitter systems appear to be targeted during therapy.

For over 50 years, traditional mood stabilizers such as lithium have been the mainstay of therapy in bipolar disorder. However, increasingly atypical antipsychotics are also establishing themselves, with several agents having received regulatory approval for use in both bipolar depression and mania.

Of the atypicals, olanzapine ${ }^{28}$ and quetiapine ${ }^{29}$ have shown significantly greater efficacy than placebo in the treatment 
of bipolar depression. Both agents are known to antagonize $5 \mathrm{HT}_{2 \mathrm{~A}}$ receptors as well as $\mathrm{D}_{2}$ receptor blockade. Their antagonistic effects on $5 \mathrm{HT}_{2 \mathrm{~A}}$ receptors, which are present on presynaptic dopamine neurons, are thought to lead to an increase in dopamine levels in the prefrontal cortex. It would appear therefore that a selective balance between dopamine and serotonin in specific regions of the brain is necessary in order to stabilize mood. In addition, quetiapine's metabolite $\mathrm{N}$-desalkylquetiapine, has been shown to be a potent noradrenaline re-uptake inhibitor and partial $5 \mathrm{HT}_{1 \mathrm{~A}}$ agonist, also contributing to its antidepressant activity. ${ }^{30}$ Furthermore, olanzapine also exhibits potent antagonistic activity at $\alpha_{1}$ adrenergic receptors leading to substantial increases in the firing neurons in the locus ceruleus with resulting increase in noradrenaline release in the prefrontal cortex. ${ }^{31}$

Atypicals are generally thought to owe their antimanic properties to their antagonism at dopamine receptors, although it is believed that antagonism at $\alpha_{1}$ adrenergic, $H_{1}$ histaminergic and serotonergic receptors may also play a role. However, unlike with bipolar depression, the importance of blocking $5 \mathrm{HT}_{2 \mathrm{~A}}$ serotonergic receptors in the treatment of mania is still unclear. ${ }^{32}$

\section{Asenapine}

\section{Pharmacology and mode of action}

Asenapine is novel pharmacological agent currently under clinical development for the treatment of schizophrenia and bipolar disorder. This new antipsychotic has high affinity for a number of receptors including antagonism at $5 \mathrm{HT}_{2 \mathrm{~A}}, 5 \mathrm{HT}_{2 \mathrm{~B}}$, $5 \mathrm{HT}_{2 \mathrm{C}}, 5 \mathrm{HT}_{6}$ and $5 \mathrm{HT}_{7}$ serotonergic receptor subtypes, $\alpha_{1 \mathrm{~A}}, \alpha_{2 \mathrm{~A}}$, $\alpha_{2 \mathrm{~B}}$ and $\alpha_{2 \mathrm{C}}$ adrenergic and $\mathrm{D}_{3}$ and $\mathrm{D}_{4}$ dopaminergic receptors. As with atypical antipsychotics, asenapine also exhibits an appreciable affinity for $\mathrm{D}_{2}$ receptors with a high $5 \mathrm{HT}_{2 \mathrm{~A}}: \mathrm{D}_{2}$ affinity ratio. Although similar to clozapine in its high affinity for a variety of different receptors, it has no appreciable affinity for muscarinic receptors, with the highest ratio of separation existing for its affinity for $\mathrm{D}_{2}: \mathrm{M}_{1}, \mathrm{M}_{2}, \mathrm{M}_{3}$ and $\mathrm{M}_{4}$ receptors. ${ }^{33}$

The multi-target nature of this new atypical antipsychotic agent has led to certain expectations for both its efficacy and tolerability. The higher affinity of asenapine for $5 \mathrm{HT}_{2 \mathrm{~A}}$ receptors relative to $\mathrm{D}_{2}$ receptors gives it its "atypicality" as it is an important mechanism thought to be responsible for enhanced efficacy of antipsychotics and reduced potential to cause EPS. ${ }^{34,35}$ In addition, antagonism at $5 \mathrm{HT}_{2 \mathrm{~A}}$ receptors, leading to an increase in dopamine activity in the prefrontal cortex, has also been suggested as a possible mechanism for alleviating negative symptoms ${ }^{2,35}$ and enhancing cognition ${ }^{36}$ in schizophrenia and other disorders. Findings from rat studies deduced that asenapine causes a dose-dependent increase in cortical $^{37}$ and hippocampal dopamine ${ }^{37}$, noradrenaline ${ }^{38}$ and acetylcholine ${ }^{38}$ comparable to previous reports with clozapine and quetiapine. Similarly, the $5 \mathrm{HT}_{2 \mathrm{C}}$ receptor may also have a similar role as $5 \mathrm{HT}_{2 \mathrm{~A}}$ and its antagonism has been linked to improvement in negative symptoms. ${ }^{39}$ Therefore, the combined antagonism at $5 \mathrm{HT}_{2 \mathrm{~A}}$ and $5 \mathrm{HT}_{2 \mathrm{C}}$ which occurs with asenapine may prove promising for the management of negative symptoms.

The resulting clinical effects of a high affinity for other serotonin receptor subtypes such as $5 \mathrm{HT}_{6}$ and $5 \mathrm{HT}_{7}$ are still unclear. Emerging evidence however suggests that $5 \mathrm{HT}_{6}$ antagonism may afford benefits for cognition ${ }^{40}$ and that $5 \mathrm{HT}_{7}$ antagonism may confer benefits for anxiety management and mood regulation as well as cognition. ${ }^{41}$ Such claims with asenapine however remain to be explored further. ${ }^{33}$ Similarly, activity at $\alpha$-adrenergic receptors has also been suggested to improve negative and cognitive symptoms by antagonism of $\alpha_{2}$ receptors, whereas improvement in positive symptoms is via $\alpha_{1}$ receptor antagonism. ${ }^{42}$ Since asenapine appears to have relatively high affinity for adrenergic receptors, and more specifically $\alpha_{2}$ receptors $^{43}$, it may potentially offer these therapeutic benefits.

Data from preclinical studies also suggests that antagonism at $\mathrm{D}_{3}$ receptors may help ameliorate negative and cognitive symptoms, ${ }^{44}$ although again the clinical evidence with asenapine for this is still lacking. Indeed, in animal models, asenapine did not improve cognition in rats, but rather, at doses greater than those required for antipsychotic activity, it impaired cognitive performance due to disturbance of motor function. ${ }^{45}$ This effect has also been observed with both olanzapine and risperidone. In contrast, in studies with monkeys, asenapine produced substantial improvement in executive functions which were maintained across a period of long-term dosing. ${ }^{46}$ Further studies in rat brain have indicated that chronic treatment with asenapine exerts regional and dose-dependent effects on inotropic glutamate receptors, ${ }^{47}$ thus another potential mechanism for its effectiveness in schizophrenia.

Since olanzapine and clozapine's high muscarinic receptor binding affinity is thought to be responsible for contributing to their anticholinergic adverse effects and potentially causing metabolic syndrome (via $\mathrm{M}_{3}$ antagonism), ${ }^{48}$ asenapine's minimal antimuscarinic activity means that it may therefore be less likely to cause these effects. ${ }^{33}$ In the animal models, asenapine induced a marked increase in dopamine in the nucleus accumbens compared to the core region, sharing a similar profile to other atypical antipsychotics. In addition, 
results from microdialysis and electrophysiological techniques found that asenapine potentiates prefrontal dopaminergic as well as glutaminergic transmission, indicating a highly potent antipsychotic activity with very low propensity for EPS. ${ }^{49}$ Whether this receptor binding profile and related pharmacology of asenapine will actually translate into such clinical benefits in practice still remains to be ascertained by ongoing studies in the management of schizophrenia and bipolar disorder.

\section{Pharmacokinetics}

Results from separate phase I studies assessing the pharmacokinetic interactions between asenapine and several cytochrome P450 (CYP) modulators and the glucuronyl transferase (UGT) inhibitor valproate found that asenapine exposure was increased by fluvoxamine but was otherwise minimally affected. Asenapine was found to have a maximum plasma concentration occurring at 0.5 to 1.5 hours after oral administration and an elimination half life of approximately 24 hours, following single dosing. In addition, there were no significant correlations between creatinine clearance and asenapine exposure in renal impairment. However, although mild or moderate hepatic impairment did not affect asenapine exposure, severe hepatic impairment increased exposure 7-fold. Furthermore, smoking was found not to affect exposure to asenapine therapy. ${ }^{50}$

\section{Efficacy and safety studies in schizophrenia}

In a 6-week, double-blind study investigating the efficacy and tolerability of asenapine in acute schizophrenia, ${ }^{51}$ patients were randomly assigned to receive twice daily doses of sublingual asenapine $5 \mathrm{mg}$, placebo or oral risperidone $3 \mathrm{mg}$. Results for the primary efficacy outcome measure, the Positive and Negative Syndrome Scale (PANSS) total score ${ }^{52}$ for the intention to treat population comprising 174 patients found mean changes at end point from baseline were -15.9 with asenapine, vs -5.3 with placebo $(P<0.005)$; the change with risperidone $(-10.9)$ compared with placebo however was non-significant. Asenapine produced significantly greater decreases in PANSS total scores compared with placebo from week 2 onward. ${ }^{51}$

Secondary efficacy measures included the PANSS positive subscale, which showed mean changes at endpoint from baseline of -5.5 for asenapine vs -2.5 for placebo $(P=0.01)$ and -5.1 for risperidone $(P<0.05)$. Asenapine produced significant reductions in PANSS positive subscale scores from week 3 onward. PANSS negative score results showed mean changes at endpoint from baseline of -3.2 for asenapine vs -0.6 for placebo $(P=0.01)$ and a nonsignificant change of -1.05 with risperidone compared with placebo. Significant decreases in PANSS negative subscale scores were again seen with asenapine from week 3 onward. For Clinical Global Impression-Severity (CGI-S) scores, ${ }^{53}$ both active treatments were associated with significantly greater decreases in CGI-S scores from week 4 onward. At endpoint, mean changes from baseline were -0.74 for asenapine and -0.75 for risperidone vs -0.28 for placebo ( $P<0.01$ and $P<0.005$ respectively). Overall, the main efficacy findings from this study suggest that asenapine $5 \mathrm{mg}$ twice daily is superior to placebo in treating positive and negative symptoms of schizophrenia. Risperidone $3 \mathrm{mg}$ twice daily, however, was superior to placebo in alleviating the positive symptoms but its effects on negative symptoms were non-significant compared with placebo, ${ }^{51}$ in contrast to previous studies showing significant improvements in negative symptoms with risperidone. ${ }^{10,54}$

In the same study, ${ }^{51}$ investigations into the safety and tolerability of asenapine found that $83 \%$ of patients assigned to the drug experienced at least 1 adverse event compared with $79 \%$ of patients assigned to placebo and $90 \%$ assigned to risperidone. The most frequently reported adverse events in the asenapine group were insomnia (11\%), somnolence (11\%), nausea (11\%) and anxiety $(10 \%) .^{51}$

The incidence of clinically significant weight gain with asenapine was equivalent to that seen with placebo, whereas the incidence with risperidone was higher, in accordance with previous reports. Similarly, asenapine had minimal effects on prolactin and metabolic parameters. The proportion of patients with normal baseline prolactin levels but with post-baseline levels of $\geq 2$ times the laboratory upper limit of normal (ULN) were $9 \%, 2 \%$ and $79 \%$ for asenapine, placebo and risperidone groups respectively. Similarly, post-baseline fasting glucose levels $\geq 20 \%$ above ULN were observed in $14 \%, 12 \%$ and $20 \%$ of patients assigned asenapine, placebo and risperidone respectively. Moreover, mean changes from baseline in total cholesterol were $-0.4,-1.7$ and $+2.3 \mathrm{mmol} / \mathrm{L}$ and mean changes in fasting triglycerides were $0,-0.1$ and $0 \mathrm{mmol} / \mathrm{L}$ for asenapine, placebo and risperidone groups respectively. ${ }^{51}$

Cardiovascular assessments found no clinically important differences between the groups with respect to blood pressure, heart rate and ECG changes. ${ }^{51}$

A further study examined the long-term safety of asenapine in patients with schizophrenia. ${ }^{55}$ The phase III, double-blind, 1-year-long trial included 1219 patients, 
randomly assigned (3:1 ratio) to asenapine 10 to $20 \mathrm{mg}$ and olanzapine 20 to $40 \mathrm{mg}$ a day. The 2 groups were comparable in terms of frequency of adverse events experienced $(60 \%$ and $61 \%$ in asenapine and olanzapine groups respectively) and withdrawals due to serious adverse events $(6.3 \%$ and $6.8 \%$ respectively). ${ }^{55}$

In contrast, differences were apparent with regards to incidence of EPS ( $18 \%$ vs $8 \%$ ), mean weight gain (1.6 kg vs $5.6 \mathrm{~kg}$ ) and significant weight gain of $\geq 7 \%$ of original body weight (14.7\% vs $36.1 \%$ ) for asenapine and olanzapine groups respectively. Cardiovascular assessments found that the incidence of QTcF (Fridericia's correction formula) $>500 \mathrm{~ms}$ or prolongation $>60 \mathrm{~ms}$ was $0 \%$ and $0.3 \%$ for asenapine and olanzapine respectively. In addition, both groups showed small mean declines in prolactin levels and small mean changes were noted for fasting glucose, cholesterol and triglycerides. ${ }^{55}$

The effects of asenapine on cardiovascular parameters were compared with those for quetiapine and placebo in a 16-day multicenter, randomized, double-blind, parallel-group study of 148 patients with schizophrenia or schizoaffective disorder. ${ }^{56}$ Patients were randomized to one of the 4 following groups: asenapine $5 \mathrm{mg}$ twice daily for 10 days then asenapine $10 \mathrm{mg}$ twice daily for 6 days; asenapine $15 \mathrm{mg}$ twice daily for 10 days then asenapine $20 \mathrm{mg}$ twice daily for 6 days; quetiapine $375 \mathrm{mg}$ twice daily for 16 days and placebo twice daily for 16 days.

Results showed no statistically significant differences between asenapine and quetiapine and no reports of QTc interval $>500 \mathrm{~ms}$ in any patient in any group. In addition, there were no reports of QTc increase from baseline $>60 \mathrm{~ms}$ with asenapine, although there was 1 with quetiapine $375 \mathrm{mg}$ twice daily and 2 with placebo. Furthermore, exposure-response modeling depicted a small positive relationship between QTc and plasma levels of both asenapine and quetiapine. In summary, although doses of asenapine $30 \mathrm{mg}$ and $40 \mathrm{mg}$ a day (but not $10 \mathrm{mg}$ ) showed a significant QTc prolongation compared with placebo, this was comparable to the increase seen with quetiapine. ${ }^{56}$

The effects of asenapine on cognitive function were assessed in a 6-week randomized, double-blind placeboand risperidone-controlled study of 180 patients with acute exacerbation of schizophrenia. ${ }^{57}$ Patients were assigned to fixed doses of asenapine $5 \mathrm{mg}$ twice daily, risperidone $3 \mathrm{mg}$ twice daily or placebo. Patients treated with asenapine demonstrated improvement on all cognitive tests related to verbal learning and memory which are important domains of cognitive function in schizophrenia.
Overall, the effects size compared with placebo on most cognitive function measures, was greater with asenapine than with risperidone, although the authors concluded that further investigations were needed in order to confirm these results. ${ }^{57}$

\section{Efficacy and safety studies in bipolar disorder}

The efficacy of asenapine in bipolar I disorder was evaluated in two 3-week multinational, randomized, double-blind, placebo- and olanzapine-controlled trials in patients with manic or mixed episodes associated with bipolar I disorder. ${ }^{58}$ A total of 976 patients was randomly assigned in a 2:2:1 ratio to flexible-dosing of asenapine $10 \mathrm{mg}$ twice daily (adjustable to $5 \mathrm{mg}$ twice daily), olanzapine $15 \mathrm{mg}$ daily (adjustable to 5 to $20 \mathrm{mg}$ daily) or placebo treatment. Results from these 2 studies found that the lean squares (LS) mean change in Young Mania Rating Scale (YMRS) ${ }^{59}$ score from baseline to day 21 were significantly greater (all $P<0.05$ ) with asenapine $(-14.2$ and -13.1$)$ and olanzapine $(-16.1$ and -13.9$)$ than placebo $(-10.8$ and -7.4$)$ in the 2 studies respectively. The active agents demonstrated superiority as early as day 2 of treatment. ${ }^{58}$

Asenapine was well tolerated in both studies and caused low incidence of weight gain. In the all-treated population, the incidence of clinically significant weight gain was reported as $7 \%$ and $6 \%$ for asenapine, $19 \%$ and $13 \%$ for olanzapine and $1.2 \%$ and $0 \%$ for placebo in the 2 studies respectively. ${ }^{58}$

Following these 2 trials, a subsequent 9-week double-blind extension study ${ }^{60}$ was carried out comprising patients who had completed the initial 3-week phase. In addition, those who completed the 9 -week extension period were also screened for an additional 40-week extension, focusing on safety of asenapine, thus bestowing a total treatment period of 1 year. Flexible doses of asenapine 5 to $10 \mathrm{mg}$ twice daily or olanzapine 5 to $10 \mathrm{mg}$ daily were initiated at the maintenance dosages used in the initial 3-week phase. The efficacy of asenapine was assessed using the mean change from baseline in YMRS total score which was -24.4 with asenapine vs -23.9 with olanzapine. Inferential analysis indicated that asenapine was not inferior to olanzapine $(P<0.0001)$. This comparable efficacy was maintained throughout the 40 week extension phase. In addition, more than $90 \%$ of patients showed response (YMRS total score reduced by $\geq 50 \%$ ) or remission (total score $\leq 12$ ) in both groups, and rates for completion and discontinuation were similar between the groups. ${ }^{60}$ 
In terms of safety, incidence rates of treatment-related adverse events were $65.7 \%$ for asenapine and $61.7 \%$ for olanzapine. Although prolactin elevation, weight gain and metabolic syndrome were more common in the olanzapine group, EPS were more common with asenapine. ${ }^{60}$

For a comparison of asenapine's adverse effects with other antipsychotics, see Table 1.

\section{Conclusions and place in therapy}

Whilst there are a variety of antipsychotics currently available on the market, there are clearly still certain needs in the treatment of schizophrenia and bipolar disorder that have not yet been met. Available antipsychotics have shown to be effective against the positive symptoms of schizophrenia however they do little to alleviate the negative symptoms and the cognitive impairment often associated with the illness.

In addition, many of the available typical antipsychotics can cause movement disorders and atypical antipsychotics can cause considerable weight gain and serious metabolic abnormalities including diabetes. Hence, a drug that can potentially provide improvement in negative and cognitive symptoms as well as the positive symptoms of schizophrenia and which is metabolically neutral and has low rate of EPS is clearly warranted. Aripiprazole already meets some of these criteria; however, an alternative would be helpful.

Furthermore, the pharmaceutical industry has spent many years trying to develop a new drug that mimics the effectiveness of clozapine but with a much improved toxicity profile. A safer alternative to clozapine is also clearly needed, although for over 50 years now no drug has been shown to match its efficacy.
Asenapine has a high affinity for a number of receptors including antagonism at serotonergic, dopaminergic and adrenergic receptors but, unlike clozapine, it has no discernible affinity for muscarinic receptors. Studies showed that asenapine caused a significant reduction in PANSS positive and negative scores compared with placebo. Thus it may not only be effective in treating positive symptoms but also has a statistically significant advantage over placebo in treating negative symptoms, although the later may not be clinically significant. Further evidence is required in order to determine whether asenapine has advantages over placebo or other antipsychotics in terms of improving functional impairment. In bipolar disorder, asenapine showed comparable efficacy with olanzapine (which was maintained throughout a 40-week period), in patients with manic, mixed episodes or bipolar I disorder.

Asenapine appears to be well tolerated and has minimal effects on prolactin and metabolic parameters. Cardiovascular assessments found no cause for concern and asenapine's effects on QTc prolongation were comparable to quetiapine, at the higher dose range of asenapine. The incidence of EPS was higher with asenapine than olanzapine in one study.

Overall, asenapine appears to have advantages over other antipsychotics for negative symptoms of schizophrenia and possibly cognitive function, although further research is required in order to assess whether this is of clinical importance and could improve the functional ability of patients. It may have a place in therapy as an atypical antipsychotic with neutral metabolic effects. There is no evidence as yet to show that it may be useful in treatmentresistant schizophrenia, as an alternative to clozapine.

Table I Adverse effects of asenapine compared with other antipsychotics

\begin{tabular}{|c|c|c|c|c|c|c|c|}
\hline Drug & QTc prolongation & Sedation & Weight gain & Diabetes & $\begin{array}{l}\text { Extrapyramidal } \\
\text { effects }\end{array}$ & $\begin{array}{l}\text { Anti-cholinergic } \\
\text { effects }\end{array}$ & Prolactin elevation \\
\hline Amisulpride & + & - & + & + & + & - & +++ \\
\hline Aripiprazole & - & - & $+1-$ & - & + & - & - \\
\hline Asenapine & + & + & $+/-$ & - & + & - & $+1-$ \\
\hline Chlorpromazine & ++ & +++ & ++ & ++ & ++ & ++ & ++ \\
\hline Clozapine & + & +++ & +++ & +++ & - & +++ & - \\
\hline Haloperidol & + & + & + & + & +++ & - & +++ \\
\hline Olanzapine & + & ++ & +++ & +++ & $+l-$ & + & + \\
\hline Quetiapine & ++ & ++ & ++ & ++ & - & - & - \\
\hline Risperidone & + & + & ++ & ++ & + & + & +++ \\
\hline Sulpiride & + & - & + & + & + & - & +++ \\
\hline Ziprasidone & ++ & + & $+1-$ & - & $+1-$ & - & $+1-$ \\
\hline
\end{tabular}

Abbreviations: +++, high incidence/severity; ++, moderate incidence/severity; +, low incidence/severity;-, very low incidence/severity. Adapted from The Maudsley Prescribing Guidelines 10th Edition.61 


\section{Disclosures}

Professor Taylor has received consultancy fees, lecturing honoraria and/or research funding from AstraZeneca, Janssen-Cilag, Servier, Sanofi-Aventis, Lundbeck, BristolMyers Squibb, Novartis, Eli Lilly and Wyeth. Ms Bishara has no conflict of interests.

\section{References}

1. Kapur S, Agid O, Mizrahi R, Li M. How antipsychotics work-from receptors to reality. NeuroRx. 2006;3(1):10-21.

2. Meltzer HY, Li Z, Kaneda Y, Ichikawa J. Serotonin receptors: their key role in drugs to treat schizophrenia. Prog Neuropsychopharmacol Biol Psychiatry. 2003;27(7):1159-1172.

3. Rowley M, Bristow LJ, Hutson PH. Current and novel approaches to the drug treatment of schizophrenia. J Med Chem. 2001;44(4):477-501.

4. Kapur S, Zipursky R, Jones C, Remington G, Houle S. Relationship between dopamine D2 occupancy, clinical response, and side effects: a double-blind PET study of first-episode schizophrenia. Am J Psychiatry. 2000;157(4):514-520.

5. Gervin M, Barnes TRE. Assessment of drug-related movement disorders in schizophrenia. Adv Psychiatr Treat. 2000;6:332-341.

6. Cavallaro R, Smeraldi E. Antipsychotic-induced tardive dyskinesia. Recognition, prevention and management. CNS Drugs. 1995;4(4):278-293.

7. Haddad PM, Wieck A. Antipsychotic-induced hyperprolactinaemia: mechanisms, clinical features and management. Drugs. 2004;64(20):2291-2314.

8. Bouchard RH, Merette C, Pourcher E, et al. Longitudinal comparative study of risperidone and conventional neuroleptics for treating patients with schizophrenia. The Quebec Schizophrenia Study Group. J Clin Psychopharmacol. 2000;20(3):295-304.

9. Beasley CM Jr, Tollefson G, Tran P, Satterlee W, Sanger T, Hamilton S. Olanzapine versus placebo and haloperidol: acute phase results of the North American double-blind olanzapine trial. Neuropsychopharmacology. 1996;14(2):111-123.

10. Marder SR, Meibach RC. Risperidone in the treatment of schizophrenia. Am J Psychiatry. 1994;151(6):825-835.

11. Weiss EM, Bilder RM, Fleischhacker WW. The effects of second-generation antipsychotics on cognitive functioning and psychosocial outcome in schizophrenia. Psychopharmacology (Berl). 2002;162(1):11-17.

12. Bilder RM, Goldman RS, Volavka J, et al. Neurocognitive effects of clozapine, olanzapine, risperidone, and haloperidol in patients with chronic schizophrenia or schizoaffective disorder. Am J Psychiatry. 2002;159(6):1018-1028.

13. Leucht S, Pitschel-Walz G, Abraham D, Kissling W. Efficacy and extrapyramidal side-effects of the new antipsychotics olanzapine, quetiapine, risperidone, and sertindole compared to conventional antipsychotics and placebo. A meta-analysis of randomized controlled trials. Schizophr Res. 1999;35(1):51-68.

14. National Institute for Clinical Excellence. Guidance on the use of newer (atypical) antipsychotic drugs for the treatment of schizophrenia. Health Technology Appraisal No. 43;2002. URL http://www.nice.org. uk. 2002.

15. Ashby CR Jr, Wang RY. Pharmacological actions of the atypical antipsychotic drug clozapine: a review. Synapse. 1996;24(4): 349-394.

16. Meltzer HY, Alphs L, Green AI, Altamura AC, Anand R, Bertoldi A. Clozapine treatment for suicidality in schizophrenia: International Suicide Prevention Trial (InterSePT). Arch Gen Psychiatry. 2003; 60:82-91.

17. Kane J, Honigfeld G, Singer J, Meltzer H. Clozapine for the treatment-resistant schizophrenic. A double-blind comparison with chlorpromazine. Arch Gen Psychiatry. 1988;45:789-796.
18. Meltzer HY, Bobo WV, Roy A, et al. A randomized, double-blind comparison of clozapine and high-dose olanzapine in treatmentresistant patients with schizophrenia. J Clin Psychiatry. 2008;69(2): 274-285.

19. Casey DE. Clozapine: neuroleptic-induced EPS and tardive dyskinesia. Psychopharmacology (Berl). 1989;99 Suppl:S47-S53.

20. Atkin K, Kendall F, Gould D, Freeman H, Lieberman J, O'Sullivan D. Neutropenia and agranulocytosis in patients receiving clozapine in the UK and Ireland. Br J Psychiatry. 1996;169:483-488.

21. Meltzer HY, Matsubara S, Lee JC. Classification of typical and atypical antipsychotic drugs on the basis of dopamine D-1, D-2 and serotonin2 pKi values. J Pharmacol Exp Ther. 1989;251(1):238-246.

22. Kapur S, Remington G. Dopamine D(2) receptors and their role in atypical antipsychotic action: still necessary and may even be sufficient. Biol Psychiatry. 2001;50(11):873-883.

23. Westerink BH. Can antipsychotic drugs be classified by their effects on a particular group of dopamine neurons in the brain? Eur J Pharmacol. 2002;455(1):1-18.

24. Baptista T, Kin NM, Beaulieu S, de Baptista EA. Obesity and related metabolic abnormalities during antipsychotic drug administration: mechanisms, management and research perspectives. Pharmacopsychiatry. 2002;35(6):205-219.

25. Meltzer HY, Davidson M, Glassman AH, Vieweg WV. Assessing cardiovascular risks versus clinical benefits of atypical antipsychotic drug treatment. J Clin Psychiatry. 2002;63 Suppl 9:25-29.

26. Lieberman JA. Dopamine partial agonists: a new class of antipsychotic. CNS Drugs. 2004;18(4):251-267.

27. Stahl SM. Dopamine system stabilizers, aripiprazole, and the next generation of antipsychotics, part 1, "Goldilocks" actions at dopamine receptors. J Clin Psychiatry. 2001;62(11):841-842.

28. Tohen M, Vieta E, Calabrese J, et al. Efficacy of olanzapine and olanzapine-fluoxetine combination in the treatment of bipolar I depression [published erratum: Arch Gen Psychiatry. 2004;61:176]. Arch Gen Psychiatry. 2003;60(11):1079-1088.

29. Calabrese JR, Keck PE Jr, Macfadden W, et al. A randomized, double-blind, placebo-controlled trial of quetiapine in the treatment of bipolar I or II depression. Am J Psychiatry. 2005;162(7): 1351-1360.

30. Jensen NH, Rodriguiz RM, Caron MG, Wetsel WC, Rothman RB, Roth BL. N-desalkylquetiapine, a potent norepinephrine reuptake inhibitor and partial 5-HT1A agonist, as a putative mediator of quetiapine's antidepressant activity. Neuropsychopharmacology. 2008;33(10):2303-2312.

31. Yatham LN, Goldstein JM, Vieta E, et al. Atypical antipsychotics in bipolar depression: potential mechanisms of action. J Clin Psychiatry. 2005;66 Suppl 5:40-48.

32. Cookson J. Atypical antipsychotics in bipolar disorder: the treatment of mania. Adv Psychiatr Treat. 2008;14(5):330-338.

33. Shahid M, Walker GB, Zorn SH, Wong EH. Asenapine: a novel psychopharmacologic agent with a unique human receptor signature. J Psychopharmacol. 2009;23(1):65-73.

34. Meltzer HY. Clinical studies on the mechanism of action of clozapine: the dopamine-serotonin hypothesis of schizophrenia. Psychopharmacology (Berl). 1989;99 Suppl:S18-S27.

35. Meltzer HY. The role of serotonin in antipsychotic drug action. Neuropsychopharmacology. 1999;21(2 Suppl):106S-115S.

36. Roth BL, Hanizavareh SM, Blum AE. Serotonin receptors represent highly favorable molecular targets for cognitive enhancement in schizophrenia and other disorders. Psychopharmacology (Berl). 2004;174(1):17-24.

37. Tarazi FI, Moran-Gates T, Wong EH, Henry B, Shahid M. Differential regional and dose-related effects of asenapine on dopamine receptor subtypes. Psychopharmacology (Berl). 2008;198(1):103-111.

38 Huang M, Li Z, Dai J, Shahid M, Wong EH, Meltzer HY. Asenapine increases dopamine, norepinephrine, and acetylcholine efflux in the rat medial prefrontal cortex and hippocampus. Neuropsychopharmacology. 2008;33(12):2934-2945. 
39. Reynolds GP, Yao Z, Zhang X, Sun J, Zhang Z. Pharmacogenetics of treatment in first-episode schizophrenia: D3 and 5-HT2C receptor polymorphisms separately associate with positive and negative symptom response. Eur Neuropsychopharmacol. 2005;15(2):143-151.

40. Neale AC, Jenkins H, Amend D, Lesen M. A 14 day dose escalation, double-blind, randomized, placebo-controlled study of SB518 in adult patients with schizophrenia [abstract]. Neuropsychopharmacology. 2005;30 Suppl 1:S54

41. Hedlund PB, Sutcliffe JG. Functional, molecular and pharmacological advances in 5-HT7 receptor research. Trends Pharmacol Sci. 2004;25(9):481-486.

42. Svensson TH. Alpha-adrenoceptor modulation hypothesis of antipsychotic atypicality. Prog Neuropsychopharmacol Biol Psychiatry. 2003;27(7):1145-1158.

43. Ghanbari R, El MM, Shahid M, Blier P. Electrophysiological characterization of the effects of asenapine at 5-HT(1A), 5-HT(2A), alpha(2)-adrenergic and $\mathrm{D}(2)$ receptors in the rat brain. Eur Neuropsychopharmacol. 2009;19(3):177-187.

44. Joyce JN, Millan MJ. Dopamine D3 receptor antagonists as therapeutic agents. Drug Discov Today. 2005;10(13):917-925.

45. Marston HM, Young JW, Martin FD, et al. Asenapine effects in animal models of psychosis and cognitive function. Psychopharmacology (Berl). 2009

46. Jentsch JD, Shahid M, Wong E, Roth RH. Asenapine improves cognitive function in monkeys repeatedly exposed to the psychotomimetic drug phencyclidine. Schizophr Res. 2006;81:85.

47. Tarazi FI, Choi YK, Gardner M, Wong EH, Henry B, Shahid M. Asenapine exerts distinctive regional effects on ionotropic glutamate receptor subtypes in rat brain. Synapse. 2009;63(5):413-420.

48. Johnson DE, Yamazaki H, Ward KM, et al. Inhibitory effects of antipsychotics on carbachol-enhanced insulin secretion from perifused rat islets. Diabetes. 2005;54(5):1552-1558.

49. Franberg O, Wiker C, Marcus MM, et al. Asenapine, a novel psychopharmacologic agent: preclinical evidence for clinical effects in schizophrenia. Psychopharmacology (Berl). 2008;196(3):417-429.
50. Peeters P, de Greef R, Hulskotte E, et al. Asenapine: an overview of phase I pharmacokinetic studies. 2009. Paris, France, Poster presented at 9th World Congress of Biological Psychiatry, 28 June-2 July 2009.

51. Potkin SG, Cohen M, Panagides J. Efficacy and tolerability of asenapine in acute schizophrenia: a placebo- and risperidone-controlled trial. J Clin Psychiatry. 2007;68(10):1492-1500.

52. Kay SR, Fiszbein A, Opler LA. The positive and negative syndrome scale (PANSS) for schizophrenia. Schizophr Bull. 1987;13(2):261-276.

53. Guy W. The Clinical Global Impressions Scale. In: Guy W, ed. ECDEU Assessment Manual for Psychopharmacology Rev Ed. Rockville, MD: National Institute of Mental Health, 1976:157-169.

54. Chouinard G, Jones B, Remington G, et al. A Canadian multicenter placebo-controlled study of fixed doses of risperidone and haloperidol in the treatment of chronic schizophrenic patients. J Clin Psychopharmacol. 1993;13(1):25-40.

55. Emsley R, Doelder PD, Schoemaker J, Naber D. Long-term safety of asenapine in patients with schizophrenia. Schizophr Res. 2008; 98 Suppl 1:48.

56. Preskorn S, Chapel S, Panagides J. Effect of asenapine versus quetiapine and placebo on QTc interval in patients with schizophrenia. Eur Neuropsychopharmacol. 2007;17 Suppl 4:S453.

57. Fleming K, Potkin SG, Binneman B, Keller D, Alphs L, Panagides J. Effects of asenapine on cognitive function in acute schizophrenia: a placebo- and risperidone-controlled trial. Eur Neuropsychopharmacol. 2007;17 Suppl 4:S466.

58. McIntyre R, Hirschfeld R, Alphs L, Cohen M, Macek T, Panagides J. Randomized and placebo-controlled studies of asenapine in the treatment of acute mania in bipolar I disorder. Schizophr Res. 2008;98 Suppl 1:5-6.

59. Young RC, Biggs JT, Ziegler VE, Meyer DA. A rating scale for mania: reliability, validity and sensitivity. Br J Psychiatry. 1978;133:429-435.

60. McIntyre R, Alphs L, Cohen M, Keller DS, Macek T, Panagides J. Long-term double-blind extention studies of asenapine vs. olanzapine in patients with bipolar mania. Schizophr Res. 2008;98 Suppl 1:48.

61. Taylor D, Paton C, Kapur S. The Maudsley Prescribing Guidelines, 10th Edn. London, UK: Informa Healthcare; 2009.
Neuropsychiatric Disease and Treatment

\section{Publish your work in this journal}

Neuropsychiatric Disease and Treatment is an international, peerreviewed journal of clinical therapeutics and pharmacology focusing on concise rapid reporting of clinical or pre-clinical studies on a range of neuropsychiatric and neurological disorders. This journal is indexed on PubMed Central, the 'PsycINFO' database and CAS, and is the official

\section{Dovepress}

journal of The International Neuropsychiatric Association (INA). The manuscript management system is completely online and includes a very quick and fair peer-review system, which is all easy to use. Visit http://www.dovepress.com/testimonials.php to read real quotes from published authors. 